\title{
Foreword
}

\section{Science and Technology in Lighting and Vision for Transportation}

\section{Yoshihiro SUDA}

\section{Chief Editor for Special Articles}

The University of Tokyo

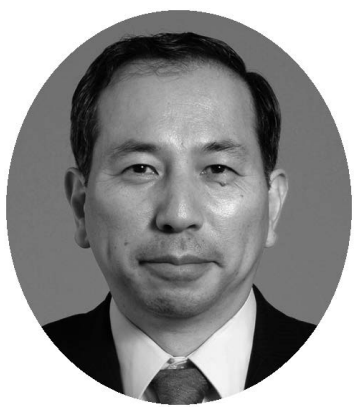

In recent years we have seen a widespread use of LED lights in transportation applications such as highway tunnel lighting, public road traffic lights and vehicle headlights. Progress in the science of vision also contributes to the development of vehicle technology and transportation engineering. The Intelligent Transportation Systems (ITS) is integrating the activities of infrastructure and vehicles with the communication technologies, contributing to transportation safety and bringing solutions to environmental and energy issues. For ITS, vision technology is of central role and importance. For the public transportation system, the use of LED lighting together with new technology of vision improves the comfort of passengers both in trains and automobiles.

This Special Issue of the Journal of Light and Visual Environment includes ten papers related to transportation technology from infrastructure and vehicles. Three papers focus on tunnel lighting. In these papers a new approach and evaluation are proposed. Another three papers discuss visual issues of automobile drivers. New concepts of the use of lighting and display are proposed. The study of vision in the passenger cars and train to improve comfort is another interesting area covered by three more papers. The final tenth paper is related to the safety of maritime traffic.

The papers in this Special Issue cover an interesting range of topics in lighting and vision for transportation from different viewpoints. The Journal of Light \& Visual Environment will continue to promote the research and development in the field of transportation. 